\title{
Creating Sustainable and Efficient Transport Interchanges: Some Findings of the City-HUB Project
}

\author{
Odile Heddebaut* \\ University of Paris Est, France \\ *Corresponding author: Odile Heddebaut, University of Paris Est, IFSTTAR AME-DEST, France, Email: odile.heddebaut@ifsttar.fr
}

Submission: 眥 July 25, 2018; Published: 眥 August 17, 2018

\begin{abstract}
This paper presents a European research project on urban mobility City-HUB. After the brief description of the City-HUB organization, model and interchanges studied, the paper shows and discusses the main findings of the project.
\end{abstract}

Keywords: City-HUB; Multimodal interchanges; Seamless travels; Interchanges impacts

\section{Introduction}

Urban transport exchange hubs play a key role as an integral part of the transport networks by facilitating relations between public transport modes but also have a function in the city urban planning and in-service facilities [1]. Time savings, urban integration, better use of waiting times and improved operating models are some of the expected benefits of developing efficient city-hubs [2,3]. However, although interchanges are crucial for improving accessibility, there are still problems remaining such as seams or bottlenecks, which are mainly reported in the coordination between the different transport modes and the use of the information systems and management model. In order to examine a part of these problems, the three years (September 2012-February 2015) City-HUB consortium of nine European research institutes from nine countries belonging to the European conference of transport research institutes (ECTRI) project studied 27 multimodal interchanges [4].

This research was conducted firstly through the analysis of 16 case studies and five pilot interchanges case studies and six validation case studies. Then were conducted semi-structured interviews with managers, planers, and transport operators. In the pilot interchanges, users' surveys were conducted. Then it was possible to create the City-HUB model taking into account the governance structure of the interchange, the different kind of services that should be present inside such a city-hub, and how the quality is perceived through the users' practices and to sort out what kind of requirement they want to be implemented in the city-hub. It contributes to the design and operation of intermodal public transport systems that are seamless, attractive, clean and safe, by bringing together recognized experts in design and urban integration, transport operators and professionals, regional and local authorities and user organizations. The paper presents and discusses the main findings of this City-HUB project.

\section{The city-hub objectives}

The first objective was to test and validate the City-HUB model for the improvement of integrated approaches to inter-modality management, control and exploitation in different European countries. The second objective was to achieve efficient multimodal interchanges by reducing their carbon footprint and maximizing the interest of new technologies for mobility, virtual communications and travel, reducing accidents and promoting healthier lifestyles. The third objective was to achieve a broad implementation of integrated mobility policies for all (by offering more opportunities for citizens to access jobs, care, education and training, trade and leisure). The fourth objective was to obtain public transport planning approval that satisfies social, environmental and mobility efficiency criteria in the most economical and efficient manner; and the fifth objective was to contribute to the development of intermodality standards, minimum conditions, quality of management, examples of good practice and levels of transport service in Europe.

\section{The city-hub interchanges studied}

The multimodal interchanges studied are located in the Czech Republic, Finland, France, Greece, Hungary, the Netherlands, Norway, Spain and the United Kingdom. They are split into the pilot case study and the validation case studies and reported on Figure 1. A four-step model has been schemed. The first step consists to identify the needs and issues arising from a city-hub project when planners want to implement one, the second step is to validate and 
secure its feasibility particularly by developing complementary policies and integrated development plans that could be linked with economic development plans or urbanism plans, the third step determine the implementation conditions and interactions with the environment by providing energy efficiency and a good integration in the city, and finally the fourth step represents the way to evaluate the functioning and the performance of the city-hub [4].

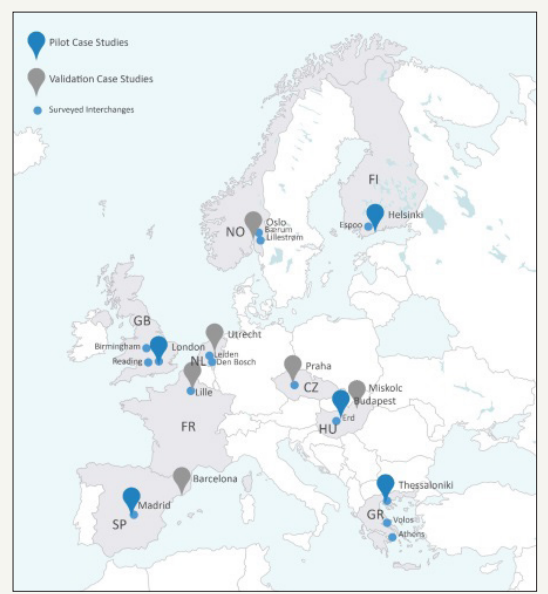

Figure 1: The location of the city-hubs studied.

27 multimodal interchanges were studied including 5 pilot cases and 6 cases to validate the City-HUB model. These different intermodal interchanges have also been characterized depending of their type of transport service, that is to say if they provide services at local, national, regional or international level, the number of transport modes reaching the city-hub (railways, underground, buses, coaches, and shared public and private transports) and their daily passengers. A typology of the different interchanges was carried out according to their size, the number of transport modes present (rail, buses, underground, shared transport modes), and their importance in the city considering the size of the interchange, its geographical situation in the city center or in the central business district (CBD) or at the periphery, and if it can be seen as an "urban marker" particularly with its architectural design.

\section{The city-hub main findings}

Mainly all the interchanges have local and regional services and 21 of them are linking main cities at national level. But only 8 upon 27 offer international services made either by train or coaches. There is no direct relationship between the size of the city-hub, the existence of international services, the number of different transport modes in the city-hub and the ridership. Effectively, Utrecht in The Netherlands has the highest level of ridership (285,000 daily passengers) without international services. Moncloa that has the second level of ridership (265,000 daily passengers) with all categories of services but the other Spanish city-hubs studied in Madrid have no rail connections however present high levels of daily passengers such as Plaza Castilla interchange (199,544 daily passengers) and Mendez Alvaro (South Bus Station, 180,238 daily passengers) [3]. Other city-hubs only serve national destinations like the KTEL Kifousou city-hub in Athens in Greece $(27,000$ daily passengers), or even serve only regional destinations like Dejvická Terminus in Prague in the Czech Republic (150,000daily passengers) or Paseo de Gracia in Barcelona in Spain (100,000 daily passengers).

Lille Europe and Lille Flandres city-hub in France counts 120.000 persons passing daily through these railway stations, of which 10.000 persons come from the metro, tramway, buses or coaches facilities, 70.000 persons are rail passengers and 40.000 persons are using the city-hub as a place to be or a link between different neighbourhoods that ease the fluidity circulation between them. The surveys made in these five pilot sites have shown that the key factors defining a good interchange for the users are: to ensure safety and security, information, conditions for the transfer from one mode to another, emergency management, the design, services and amenities qualities, environmental quality and comfort of waiting times. The validation of the City-HUB model was tested through the 5 validation case studies in operation, through semistructured interviews towards transport authorities, developers, operators, urbanists and planers and an evaluation grid composed of criteria concerning: the design of the city-hub, accessibility, coordination between the different transport modes, amenities and services provided, safety and security, information and ease to navigate inside the city-hub.

These interviews revealed the most important criteria for a successful intermodal interchange. They are first and foremost an information and an understanding of the space with a good "universal" signage and the possibility to receive any public including those with special needs (Lille), good external and internal accessibility with good services and a judicious choice of its location in the networks (Oslo), a clear and communicative information on the other modes of transport inside the interchange hub as real time information specially in disturbance situation, reasonable distances between transport modes (Barcelona). Aspects related to improvements in environmental performance are shared according to whether the hub is new, foreseen or under renovation or already existing for a long time which would imply substantial budgets for such improvements.

It has been shown that multimodal exchanges are more likely to have an impact on the local economy and land use when transport and urban planning policies are integrated and implemented with a strong commitment from the political and operational stakeholders. New neighborhoods can emerge and urban renewal is often favored [5]. Finally, for each identified criterion that could qualify the operation of an intermodal transport hub, good practices were analyzed for each of the 5 pilot sites and the 6 validation sites of the City-HUB model. The possibilities of their application to different kinds of multimodal interchange centers according to the established typology were also considered.

\section{Discussion}

There is a discrepancy between the users' feeling and experience of the five different pilot interchanges that are mainly in 
line with the literature [6] and the vision of stakeholders in charge of implementing a city-hub. Effectively, for the users the need to feel safe seems greater than the facility of navigating inside the interchange. Conversely, the operators and planners imagine firstly how to ease the circulation into their city-hub in order to increase their performance and lower the distances between different transport modes. We have seen that points should be improved concerning the coherence between the actors of the different scales of planning and the different stakeholders, owners, operators for a better integration of the transport modes (schedules, distances, reciprocal information, etc.). Integrated ticketing would facilitate also the use of multimodal transport and their inter-modality. This could be possible if a strong commitment of all the stakeholders exist to share all the operators' travel data. The problem to be solved is that these data represent also private commercial inputs.

In some cases, integrated development plans combine the establishment of the new hub with the construction of new housing or offices either above or near the hub or even the creation of large shopping malls inside or beside these intermodal transport locations. The economic and urban impacts can be observed especially if there is a dynamic city center with a qualified population [7]. Although the direct link between the city-hub and economic development is difficult to establish, its size and role in the conurbation and in the networks linking the main national or international cities can explain the development that is taking place nearby. The city hub can also ease the city functioning and become a new place with strong fluent and intelligent connections that are seen and/or expected in "smart cities" [8].

\section{Acknowledgement}

This research was fully sponsored by the European Commission under the $7^{\text {th }}$ Framework Program with grant number 314262 .

\section{References}

1. Richer C (2008) L'émergence de la notion de «pôled'échanges»: entre interconnexion des réseaux et structuration des territories. Les Cahiers Scientifiques du Transport N 54: 101-123.

2. Krygsman S, Dijst M, Arentze T (2004) Multimodal public transport: an analysis of travel time elements and the interconnectivity ratio. Transport Policy 11(3): 265-275.

3. Vassallo JM, Ciommo DF, Garcia A (2012) Intermodal exchange stations in the city of Madrid. Transportation 39(5): 975-995.

4. Monzón A, Ciommo DF (2016) City-HUBs: Sustainable and efficient urban transport interchanges. CRC press, Taylor \& Francis, Florida, USA, p. 280.

5. Heddebaut O, Palmer D (2014) Multimodal city-hubs and their impact on economic and land use planning. Transport Research Arena 2014. Transport Solutions: from Research to Deployment-Innovate Mobility, Mobilise Innovation, Paris, France.

6. Iseki H, Taylor BD (2010) Style versus service? an analysis of user perceptions of transit stops and stations. Journal of Public Transportation 13(3): 23-48.

7. Banister D, Berechman Y (2001) Transport investment and the promotion of economic growth. Journal of Transport Geography 9(3): 209-218.

8. Heddebaut O, Ciommo DF (2017) City-Hubs for smarter cities. The case of lille "euraflandres" interchanges. European Transport Research Review, pp. 1-14.
Creative Commons Attribution 4.0 International License

For possible submissions Click Here

\section{Submit Article}

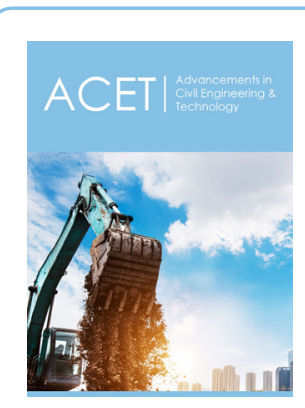

Advancements in Civil Engineering \& Technology

\section{Benefits of Publishing with us}

- High-level peer review and editorial services

- Freely accessible online immediately upon publication

- Authors retain the copyright to their work

- Licensing it under a Creative Commons license

- Visibility through different online platforms 